SANDIA REPORT

SAND97-1534 • UC-406

Unlimited Release

Printed June 1997

\title{
Shock Mitigation for the PFLs at the SATURN Accelerator
}

\author{
R. E. Craven
}

\section{Prepared by}

Sa ndia Nationa 1 La bora tories

Albuquerque, New Mexic o 87185 and Livermore, California 94550

Sa ndia is a mu ltip rogr am labor ator y operated by Sa ndia Cor pora tion, a Lock heed Martin Company, for the United States Department of Energy under Contraci DE-A C(4-94AL 85000.

Approved for public release; distribution is unlimited.

\section{in Sandia National Laboratories}
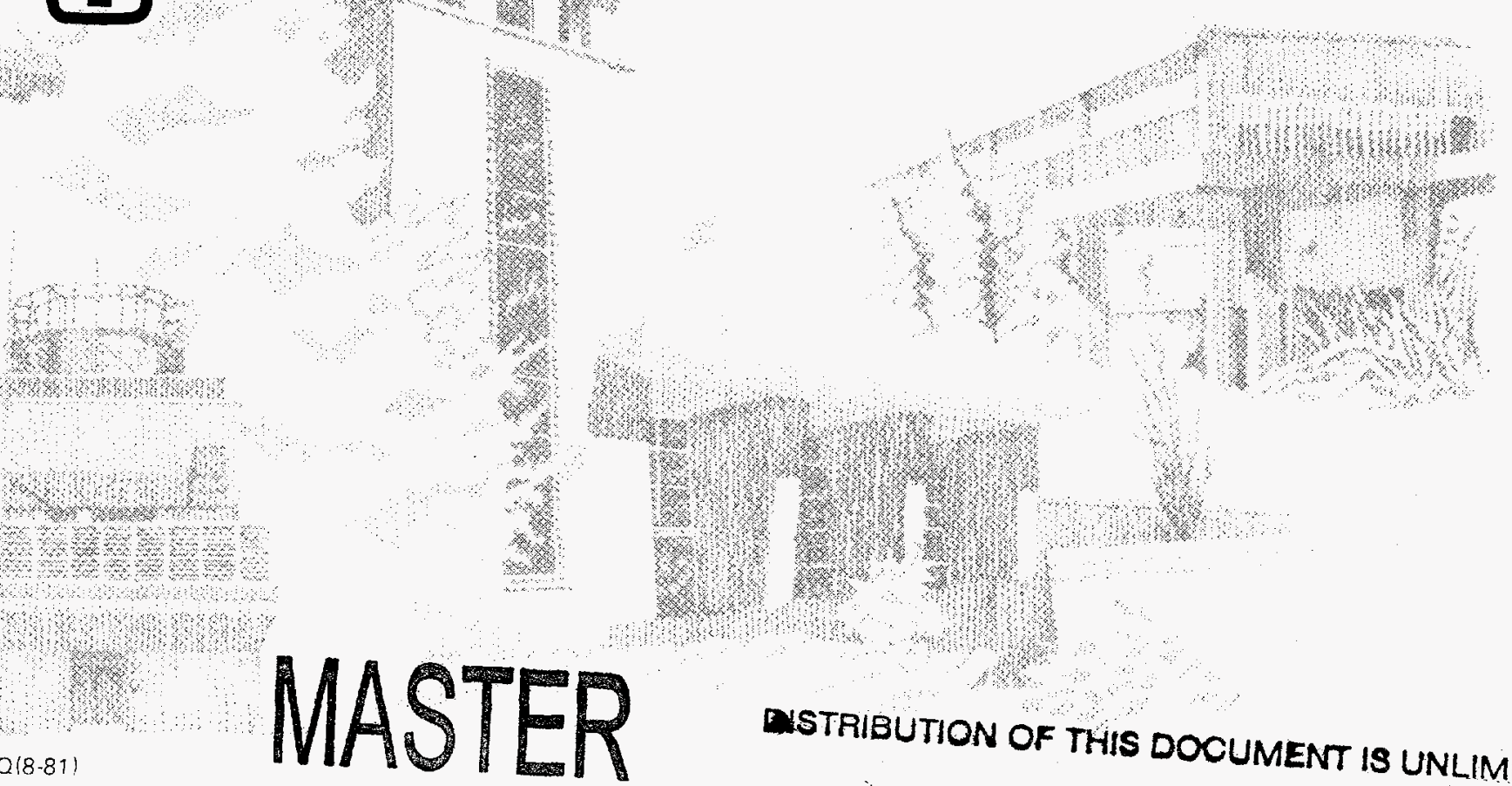

arters

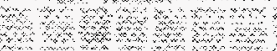

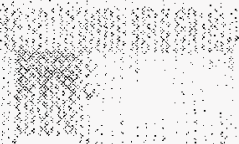




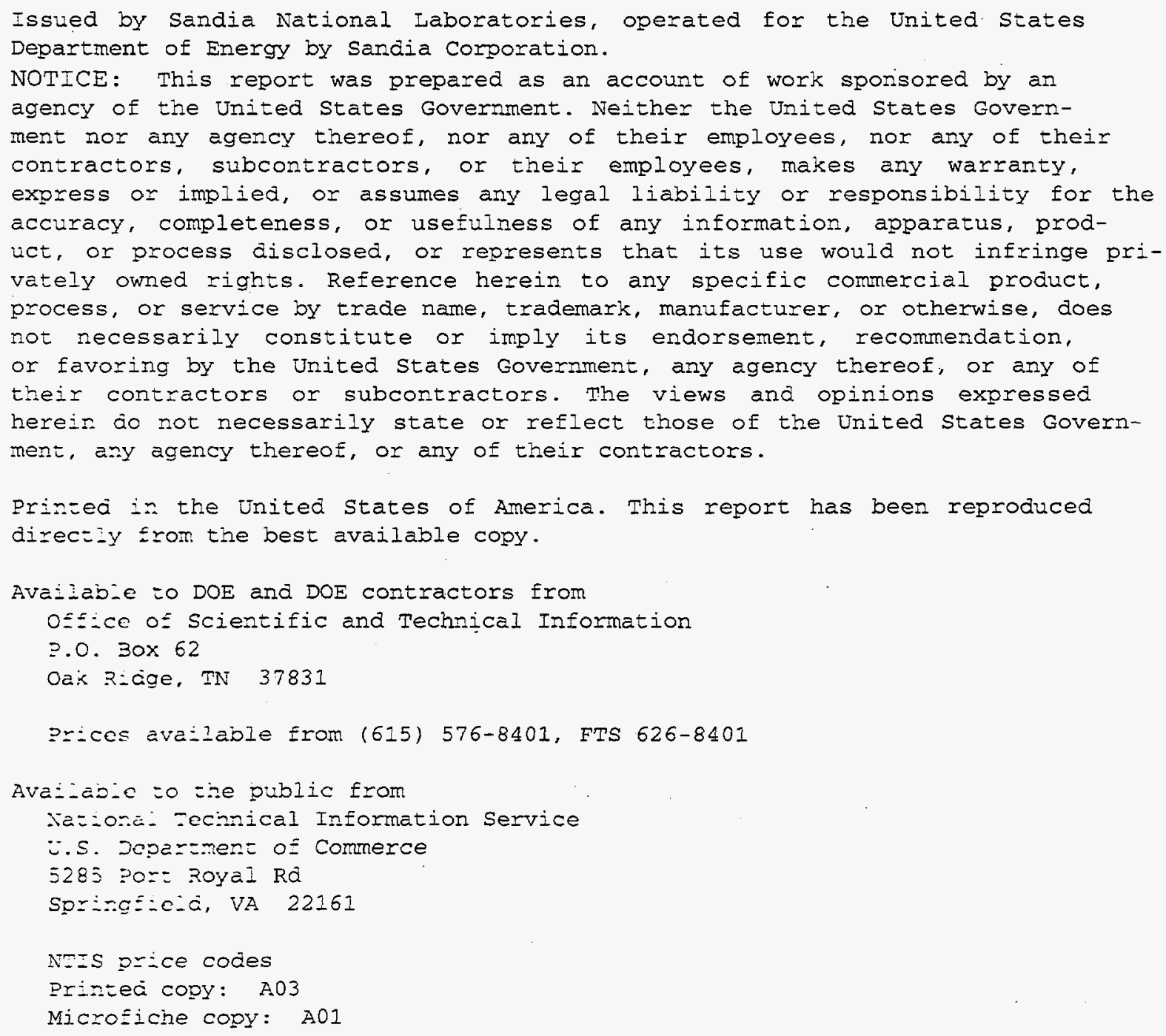




\section{DISCLAMIER}

Portions of this document may be illegible in electronic image produets. Images are produced from the best available original document. 


\title{
Shock Mitigation for the PFLs at the SATURN Accelerator
}

\author{
R. E. Craven \\ AGT Accelerator Operations Department \\ Sandia National Laboratories \\ P.O. Box 5800 \\ Albuquerque, NM 87185-1106
}

\begin{abstract}
Accelerometer measurements were made on the SATURN pulse forming lines (PFL) to determine the mechanism responsible for severe metal deformation around the water switch openings and cracking of welded seams. A reason for this problem and a solution were established. A simple shock mitigating pad under the support stand for the PFL provides more than adequate protection from shock damage and will greatly extend the useful life of the power flow sections of SATURN.
\end{abstract}




\section{Acknowledgment}

I would like to thank Derek Hughes, of Organization 9322 Experimental Design/Analysis and Computing Support, for providing me with his "Polylook" wave form analysis program for Windows 95. This proved to be an indispensable tool for analyzing the data from SATURN shots. Derek's willingness to modify his program each time I found a need for a new feature to help me do my job was especially valuable. 


\section{Contents}

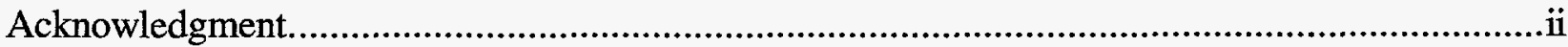

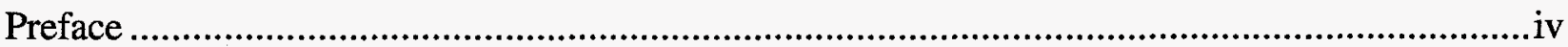

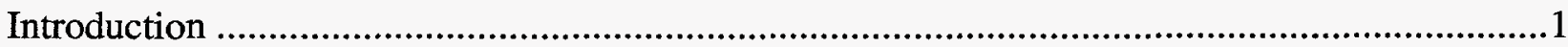

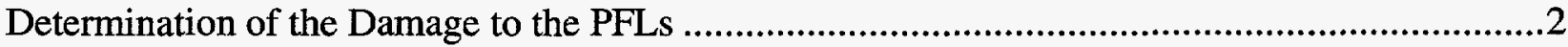

Approach to Determine the Magnitude of Damage to the PFLs........................................4

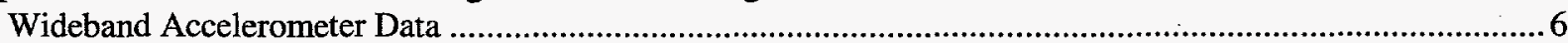

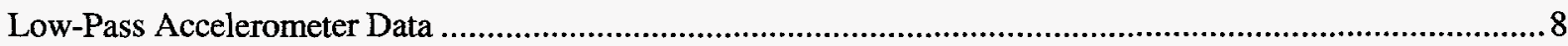

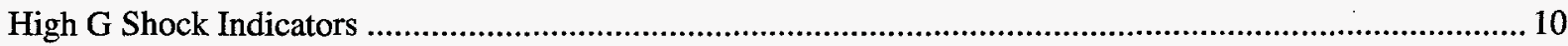

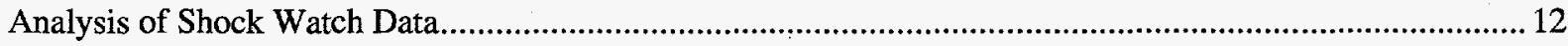

High-Frequency Vibration Effects on SATURN...........................................................13

Instrumentation and Analysis of Accelerometer Measurements ......................................15

Suggestions for Future Accelerators ....................................................................19

\section{Figures}

1. Original design welded PFL, showing damage on lower lip of water switch

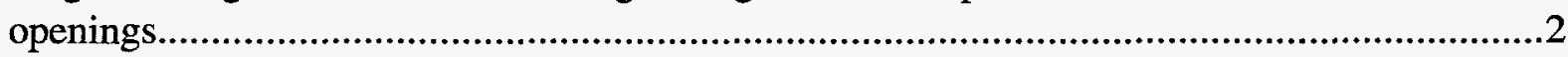

2. Modified brass nut and upper shock pad................................................................

3. Detail of pad placement and ground return mounting.......................................................5

4. Typical accelerometer mount. The microdot signal cable passes through a breeze tube for additional EMP shielding...................................................................6

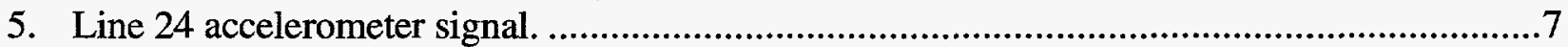

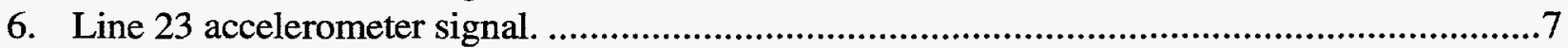

7. Accelerometer and low-pass filter mounting. The breeze tubing passes down to the floor of the tank by way of the ground plane portion of the PFL. ................................8

8. Line 23 accelerometer signal with the low-pass filter installed.............................................

9. Line 24 accelerometer signal with the low-pass filter installed.........................................

10. Placement of Media Recovery shock indicators directly under the accelerometers...............10

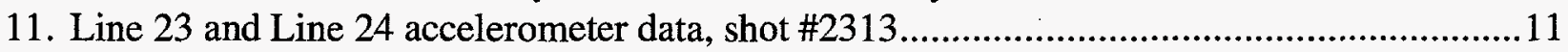

12. Typical accelerometer configuration .................................................................. 15

13. View of the bottom of the water section showing the placement of shock mitigating pads and snubbers under the bolt heads................................................16

Appendix A. Calibration Graphs for Media Recovery Shock Watch ....................................20

Appendix B. Brüel \& Kjær UA0553 and UA0559 Specification Sheet ................................22

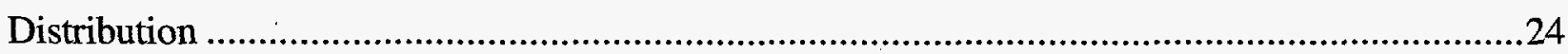




\section{Preface}

This study was the direct result of an observation of damaged pulse forming lines (PFLs) that had been removed from the SATURN accelerator. Seventeen PFLs were so badly damaged that they were affecting machine performance and had to be replaced. Losing 17 out of a total of 36 PFLs cost $\$ 200,000$ in replacement parts alone from the manufacturer. Changing these PFLs was handled during a regularly scheduled maintenance period, which minimized revenue loss. During this time, the center section stack was also rebuilt, which is in keeping with good preventive maintenance practices. The $\$ 200,000$ replacement cost is only a portion of the total dollar cost during this period; however, it should strongly make the point that proper design of components and routine preventive maintenance would have minimized this cost and extended the service life of the PFLs and the overall useful life of SATURN. 


\section{Introduction}

This document is primarily concerned with reducing peak shock loads on pulse forming lines (PFLs) and therefore will only touch briefly on the other parts of the power flow sections that directly influence the life of the PFLs. Additional details that concern the SATURN accelerator can be found in document PSI-FR-208, SATURN Electrical Design, Final Report, Pulse Sciences, Inc.

The current configuration of the SATURN accelerator is the result of a retrofit and upgrade of the Particle Beam Fusion Accelerator (PBFA) I facility completed in the mid-1980s. The modifications were a joint effort by Sandia National Laboratories, Albuquerque, New Mexico, and Pulse Sciences, Inc., San Leandro, California. Their task was to take the existing PBFA I facility and create a machine capable of supporting both plasma radiation source mode and bremsstrahlung radiation source mode.

The upgrade consisted of all new parts beyond the PFLs toward the diode. The PFLs, intermediate store, and marx generators are part of the original equipment and underwent some modifications prior to installation in the new configuration. This incorporation of original equipment into the upgrade was an appropriate cost-saving idea initially, but problems have arisen over the subsequent years of operation that now require attention.

The $\mathrm{Z}$ triplates adjacent to the PFLs are new parts and are supported on spring shock mounts. The springs allowed both radial and vertical movement. These springs also absorbed the mechanical shock that was generated by the energy delivered to the diode. Although some of its hardware vibrates loose, there is no indication of permanent damage to these parts. The PFLs, on the other hand, are bolted solidly to the floor of the steel tank and do not have any mechanism to mitigate this same mechanical shock. As a result of continual pounding, the PFLs are selfdestructing. A simple, cost-effective change that will reduce the peak shock loads and extend the life of the PFLs is presented here. 


\section{Determination of the Damage to the PFLs}

In October 1995, the SATURN accelerator facility was shut down briefly for routine maintenance and for changing 17 damaged PFLs with new units. The new PFLs were manufactured by Calcor Space Facility, Whittier, California, as were the original units.

The damaged PFLs were inspected to determine why they failed. All 17 units exhibited cracking welds and tearing metal. The openings for the water switches showed the worst damage, but the most interesting fact was that the damage was similar in all 17 units; that is, the failure mode was consistent.

The original design of the Calcor Space Facility was modified by using rivets rather than welding for joining panels together to form the finished product. The current configuration of SATURN still has 19 PFLs on line that use the older welded design.

The lower half of the water switch openings are deformed and sagging downward. This is because of water switches that have vibrated loose and have dropped down, causing preferential arcing at this point. It is also because of acceleration forces in the downward direction caused by high G loadings on the PFLs. The arcing will cause melting and pitting while the mechanical pounding will tear the aluminum. Both types of damage are shown in Figure 1.
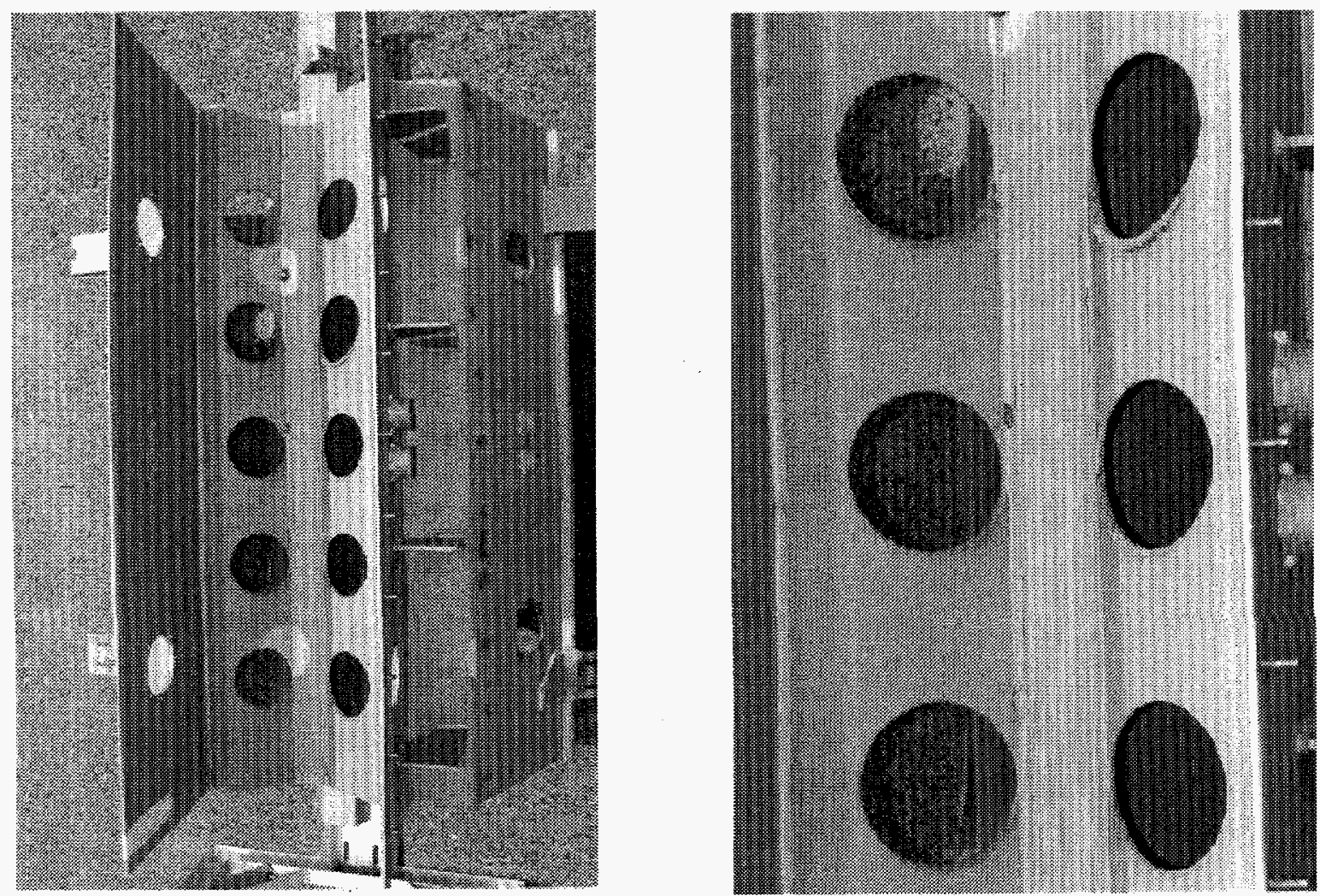

Figure 1. Original design welded PFL, showing damage on lower lip of water switch openings. 
The response of the PFL to the shock pulse is constrained to vertical motion. The shock pulse originates at the diode center section and propagates outward along the 36 lines that make up the power flow sections. The wave front moves from 32,000 feet per second to 39,000 feet per second. This imposes a horizontal shearing load on the PFL support stand bolts as well as a vertical acceleration. The PFLs' vertical motion follows the shock pulse. The 500-pound PFL is accelerated away from the floor of the water section and is stopped by the elastic limit of the bolts that hold the support stand to the floor. This is the "soft" half cycle of the shock pulse. Peak G loading is less than the other half cycle. The PFL follows this pulse in the same fashion, except that the bottom end of the PFL is rigidly fixed to the steel floor with concrete underneath. While the lower end is fixed and cannot move, the upper end of the PFL is still accelerating toward the floor. The force exerted on the aluminum structure exceeds the yield strength of the material. This is consistent with the physical damage. The result is a destructive cyclic process that is slowly destroying SATURN. 


\section{Approach to Determine the Magnitude of Damage to the PFLs}

Power flow lines 23,24 , and 25 were used for this experiment. Line 24 was chosen for the modification, while lines 23 and 25 were monitored, but not modified. This provided more flexibility in comparing results.

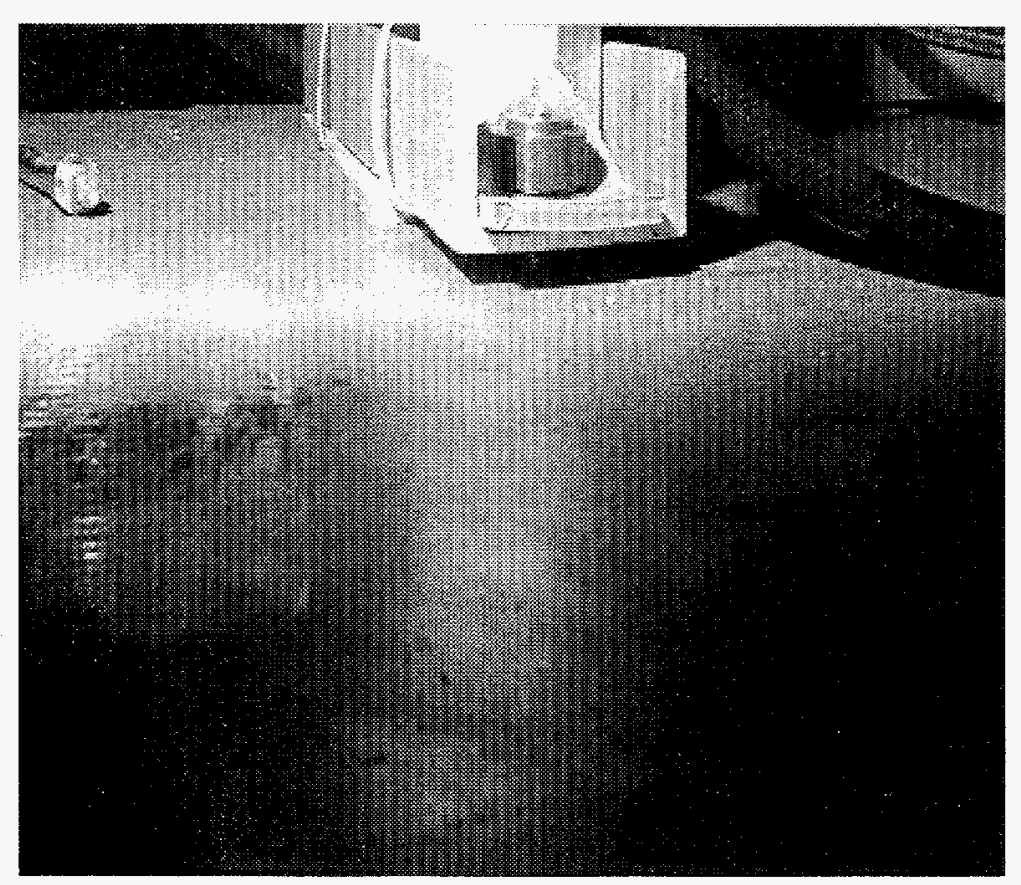

Figure 2. Modified brass nut and upper shock pad.

Figure 2 shows the support stand for the line 24 PFL mounted on polyurethane pads. There are four 3 in. $\times 5$ in. pads under the stand and four 2 in. $\times 2$ in. pads under the mounting bolts that hold the stand to the steel floor of the tank. This arrangement floats the stand between two sets of pads, so that shock loads are snubbed for both positive and negative excursions of the PFLs. A custom brass nut was created to hold the upper pad and provide increased surface area.

The polyurethane pad material used for this demonstration was originally designed as a liner for ore cars and is extremely rugged. The thickness of this pad is $0.25 \mathrm{in}$. The shore durometer is probably close to 80 . There was no documentation available on this sample; this value is a guess. It does however allow some ballpark calculations for reduction of peak shock. Figure 3 shows the placement under the support stand for the PFLs. The pads are restrained by tie wraps because vibration from each shot tended to move them out of place. A variation of this pad that could be securely fastened to the bottom of the stand would be required for a final design. 


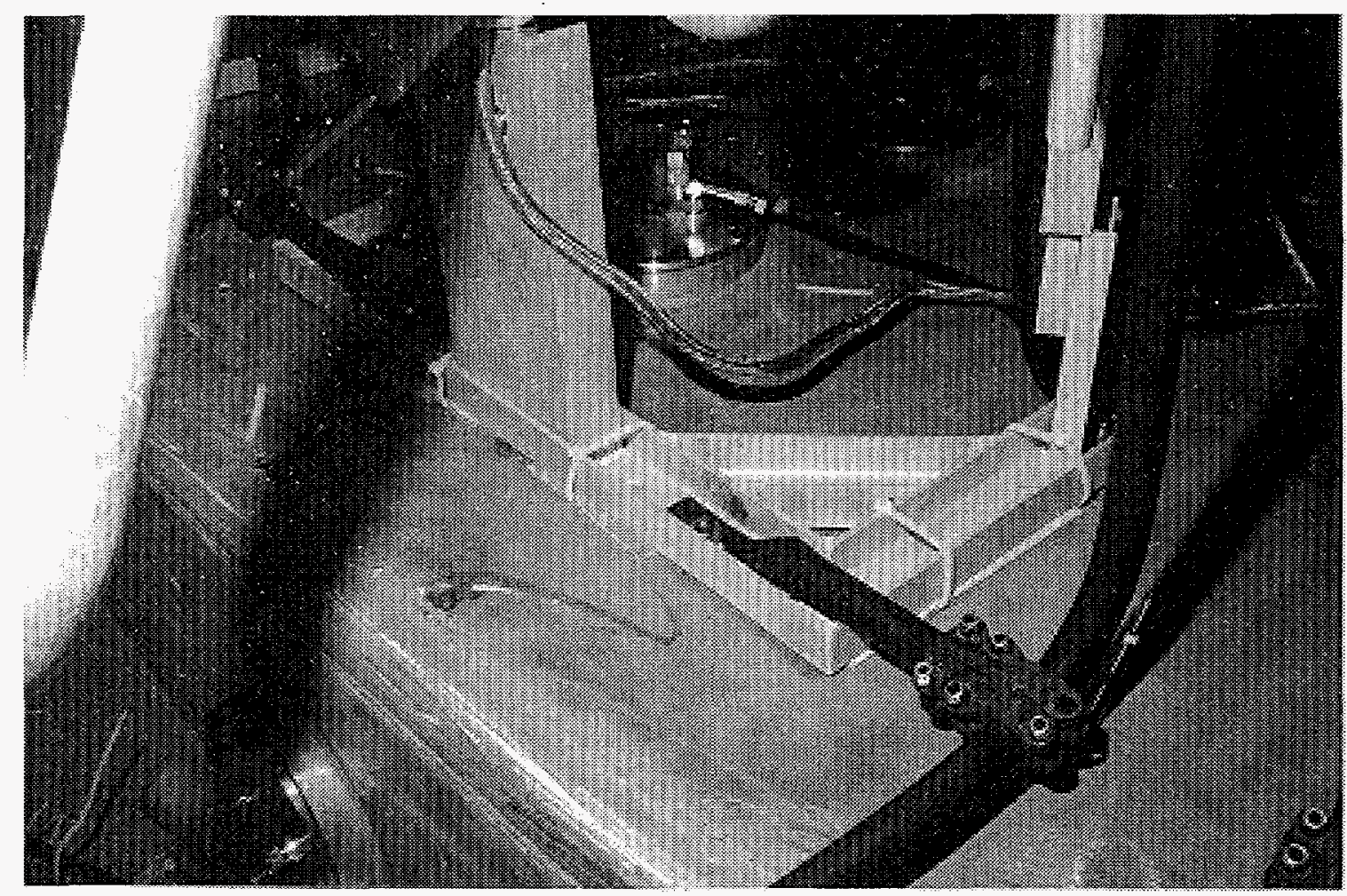

Figure 3. Detail of pad placement and ground return mounting.

The top of the PFL provided a suitable platform for mounting an accelerometer. All three lines were identically fitted with accelerometers. A 5/16 in. brass bolt was modified by drilling and tapping the head to accept a 6-32 thread. The brass bolt then replaced the steel bolt (Figure 4). This configuration placed the accelerometer as close to the vertical center axis of the PFL as possible. A second configuration was also used for a set of measurements. In this setup, a Brüel \& Kjær low-pass mechanical filter is inserted between the brass bolt and the accelerometer. This will limit the low-pass bandwidth response of the accelerometer to a maximum of $6 \mathrm{KHz}$. Specifications for this mechanical low-pass filter are provided in the appendix.

The nature of the damage to the PFLs requires that the accelerometer response be split into a full spectrum and a low band pass spectrum. 


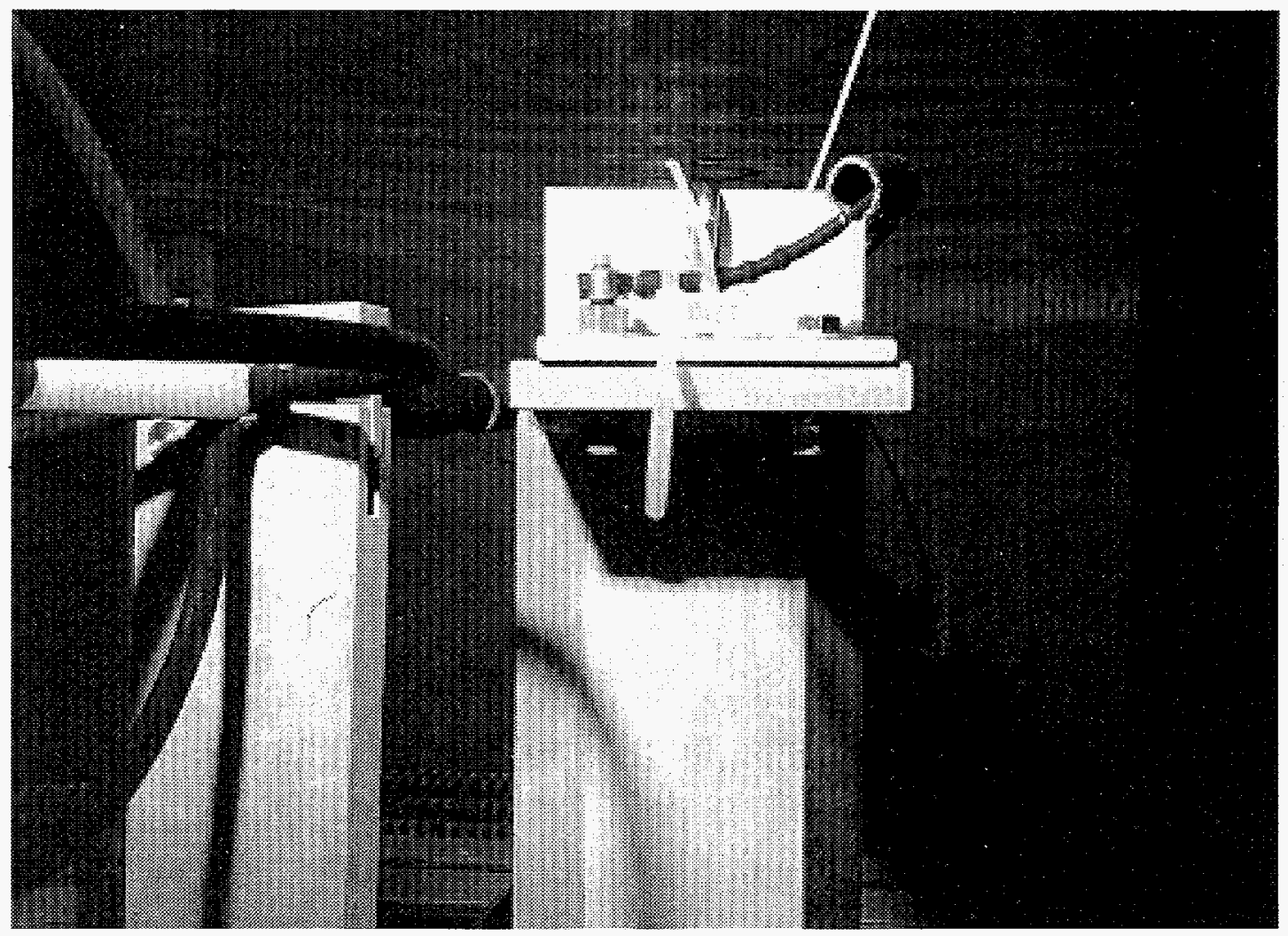

Figure 4. Typical accelerometer mount. The microdot signal cable passes through a breeze tube for additional EMP shielding.

Figure 4 details the mounting of the accelerometer to the top of the PFL. The accelerometer is electrically isolated from ground return by fiber washers and a sleeve for the mounting screw. The microdot cable is braided, providing less than $100 \%$ shielding. Breeze tubing is used to provide a second electromagnetic pulse (EMP) barrier against noise.

\section{Wideband Accelerometer Data}

Figures 5 and 6 show the full frequency response from the accelerometers on a padded PFL and a PFL that is solidly bolted to the steel floor of the water section. The frequency is in the order of 200 kilocycles, while the peak $\mathrm{G}$ loadings drop from approximately $200 \mathrm{Gs}$ to $50 \mathrm{Gs}$ merely by placing a shock mitigating pad beneath the support stand. 


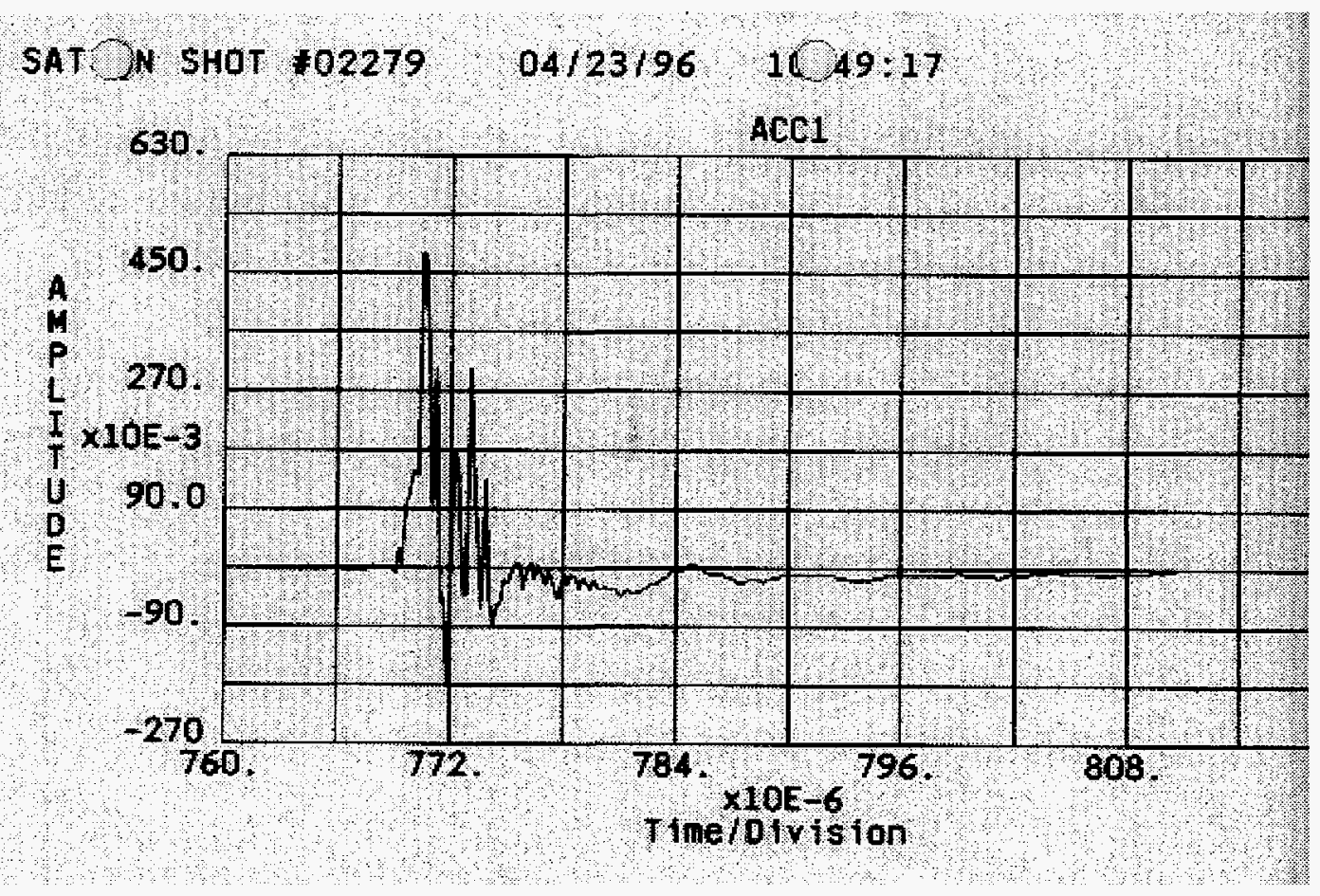

Figure 5. Line 24 accelerometer signal.

The peak amplitude is down by a factor of four from signals on line 23 and 25 . The calibration is 10 millivolt/G. Figure 5 indicates a peak value of $50 \mathrm{Gs}$ for the padded PFL.

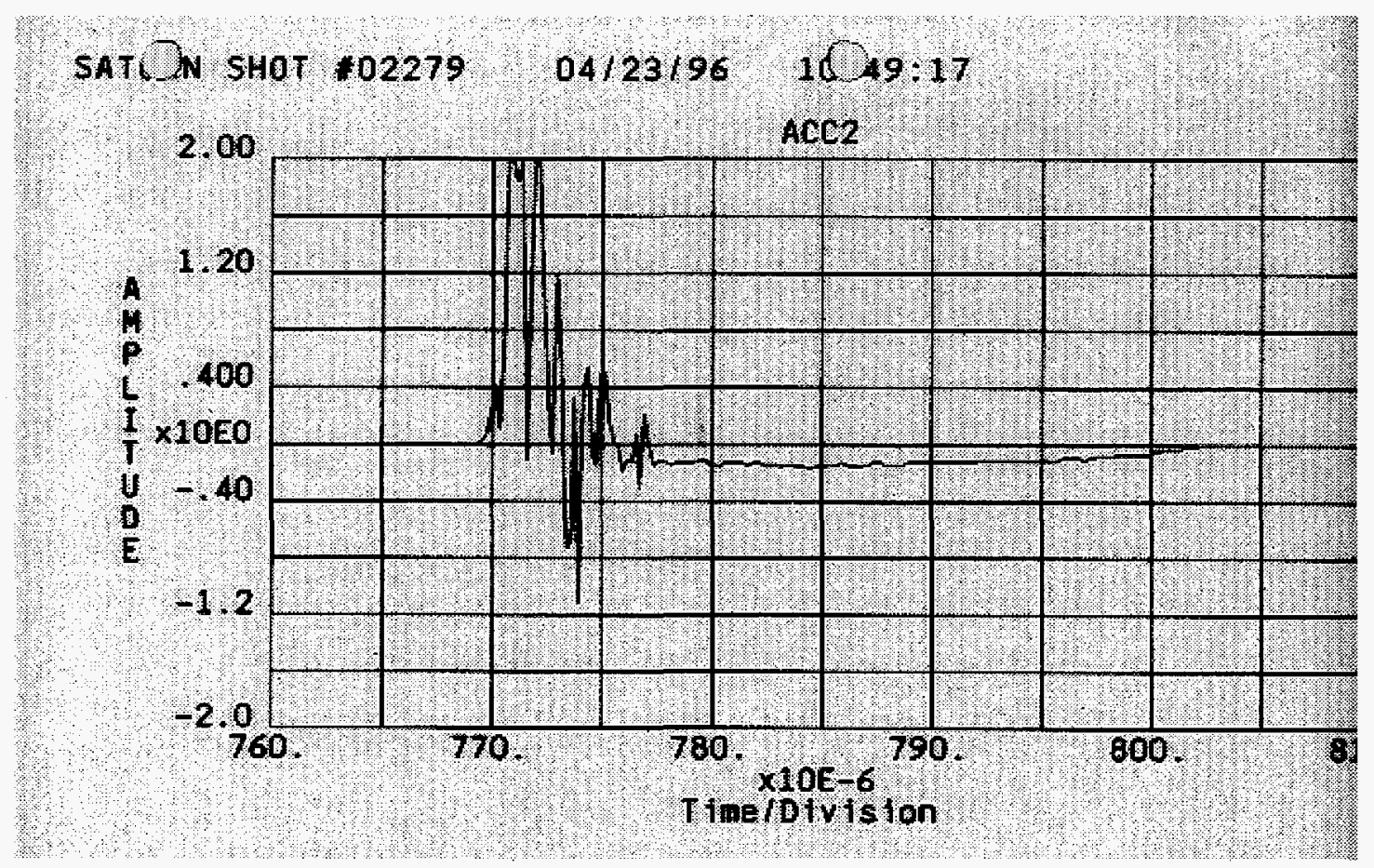

Figure 6. Line 23 accelerometer signal. 
The calibration is 10 millivolt/G. Figure 6 indicates a peak value of 200 Gs for the unpadded PFL. This PFL is solidly bolted to the bottom of the steel tank.

Peak $\mathrm{G}$ loading in Figures 5 and 6 clearly shows that peak shock has been reduced to a fourth by a simple modification.

Frequency of this shock wave is approximately $200 \mathrm{KHz}$. This portion of the shock wave spectrum is primarily responsible for bolted parts vibrating apart. The spring rate (how tight a bolted member holds) is proportional to the frequency squared.

\section{Low-Pass Accelerometer Data}

A second test configuration was installed on lines 23, 24, and 25. Three low-pass mechanical filters were purchased (Brüel \& Kjær model number UA0559) and installed between the top of the PFL and the accelerometer. These filters limit the frequency response of the accelerometer to 6 kilocycles $(-3 \mathrm{~dB})$.

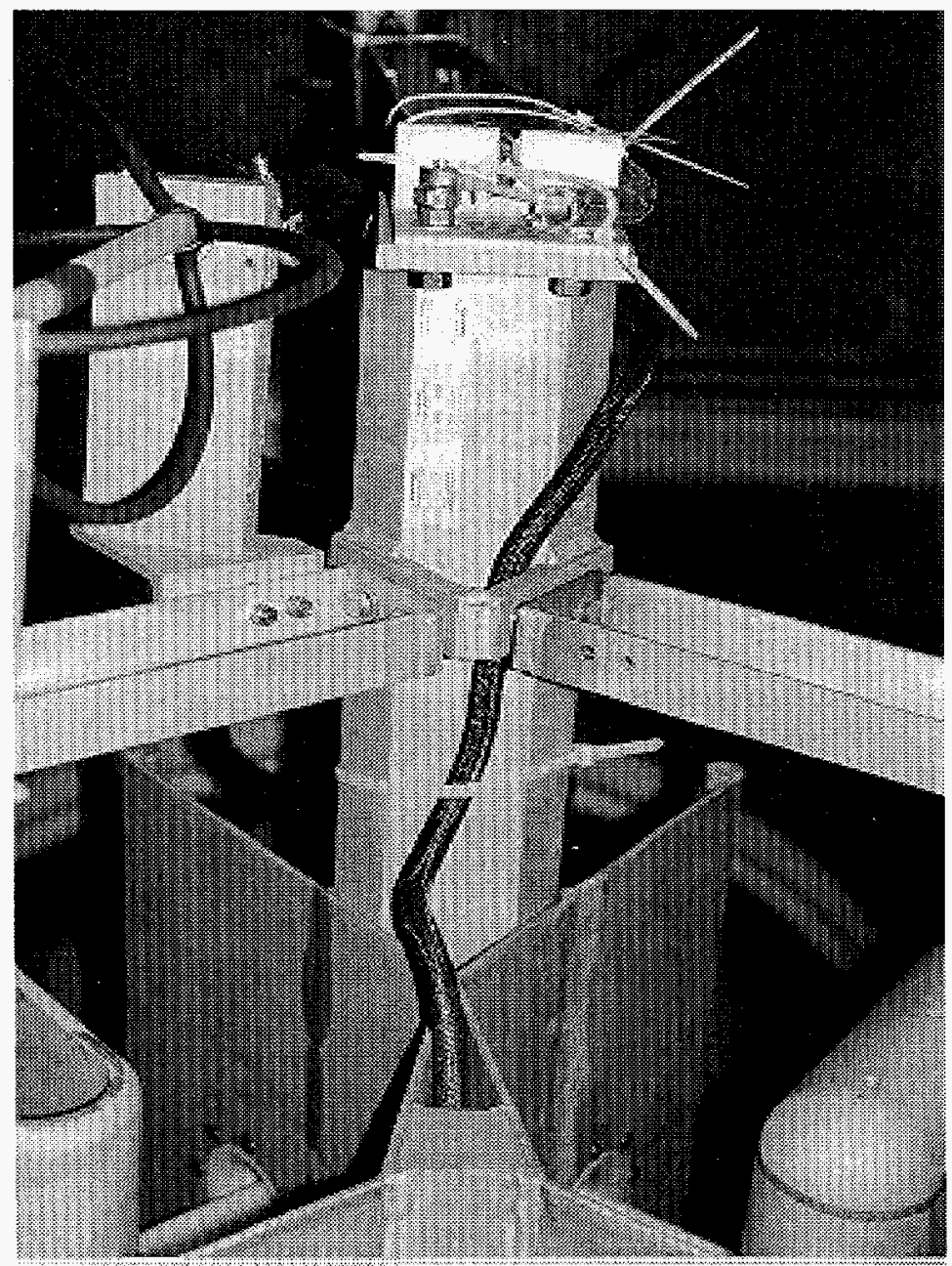

Figure 7. Accelerometer and low-pass filter mounting. The breeze tubing passes down to the floor of the tank by way of the ground plane portion of the PFL. 


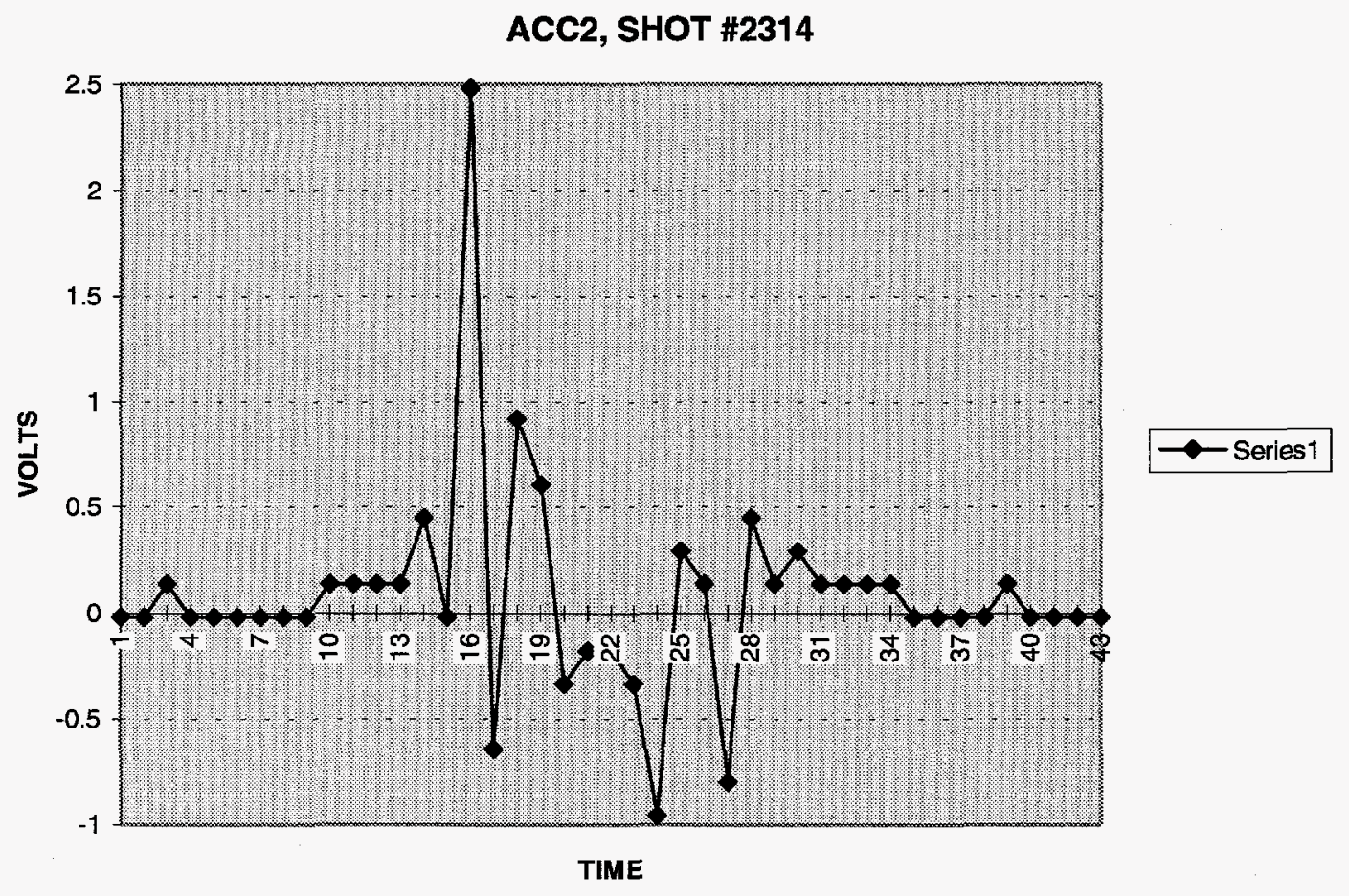

Figure 8. Line 23 accelerometer signal with the low-pass filter installed.

Figures 8 and 9 display the low-pass shock pulse. This portion of the shock spectra is primarily responsible for the metal deformation on the PFLs. The ratio of approximately 4:1 reduction in peak shock loading along with an increase in the duration that the pulse is applied is evident. The same amount of energy is applied to both PFLs, but the shock pad has limited the peak acceleration and spread the force out over time. This keeps the applied force well below the yield strength of the aluminum.

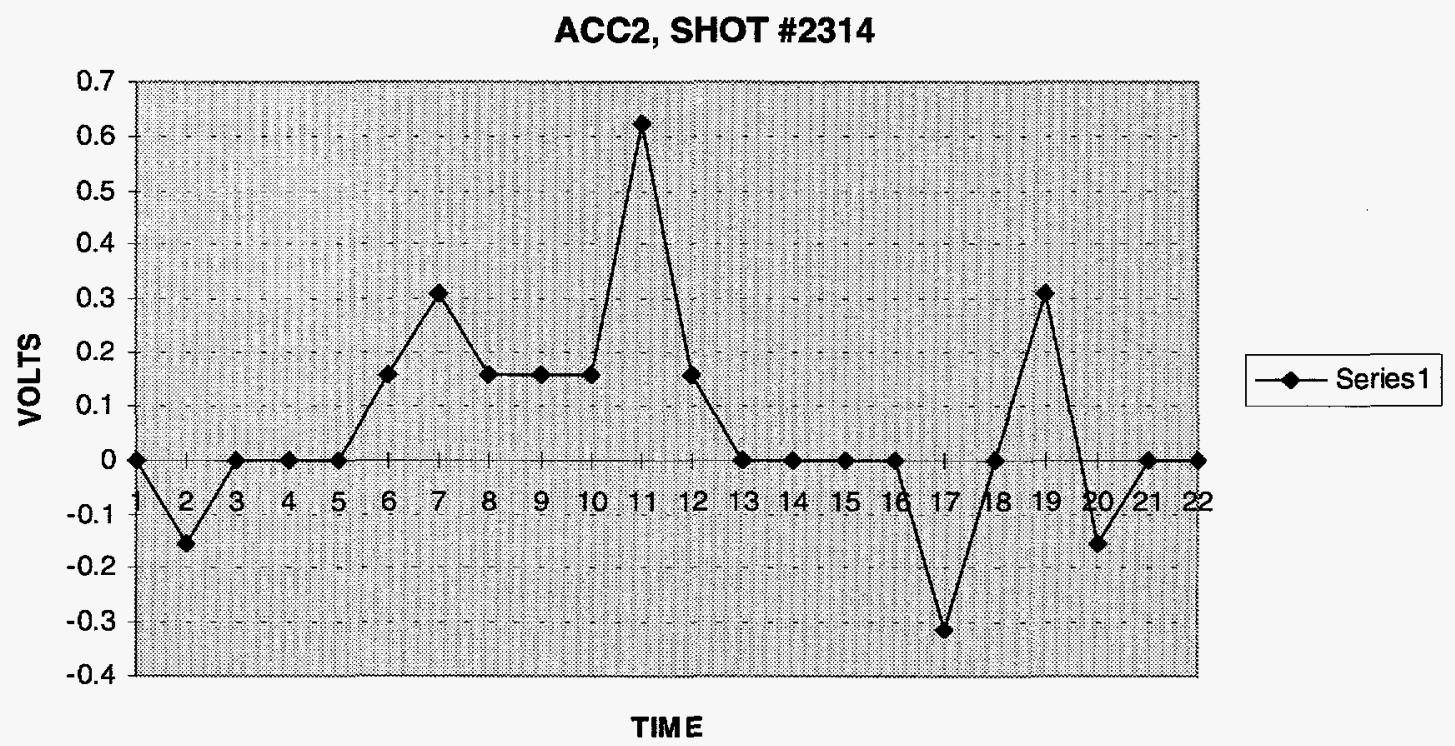

Figure 9. Line 24 accelerometer signal with the low-pass filter installed. 


\section{High G Shock Indicators}

The one-shot high $\mathrm{G}$ shock indicators were implemented for several shots to corroborate accelerometer data. These indicators respond to calibrated minimum shock level. Four levels were chosen that would work within known levels. Figure 10 shows the placement of the accelerometer and the routing of the signal cable shielded by breeze tubing as it passes down through the center of the PFL. There are three shock indicators mounted on the vertical post directly below the accelerometer.

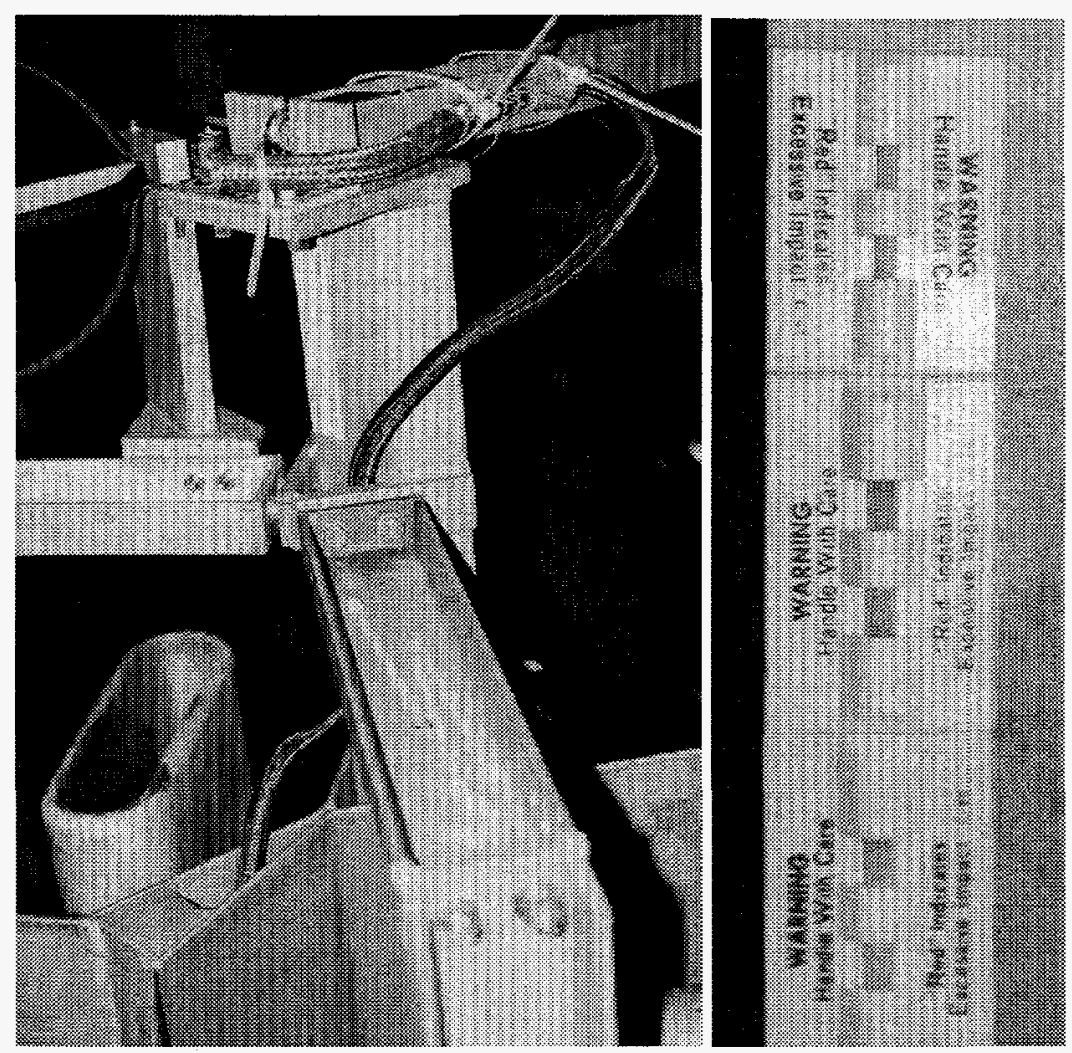

Figure 10. Placement of Media Recovery shock indicators directly under the accelerometers.

The shock indicators are a one-shot device. The clear center turns bright red when a peak $\mathrm{G}$, time-applied, product is exceeded. Four bands spanning the expected $\mathrm{min} / \mathrm{max}$ levels were chosen. 


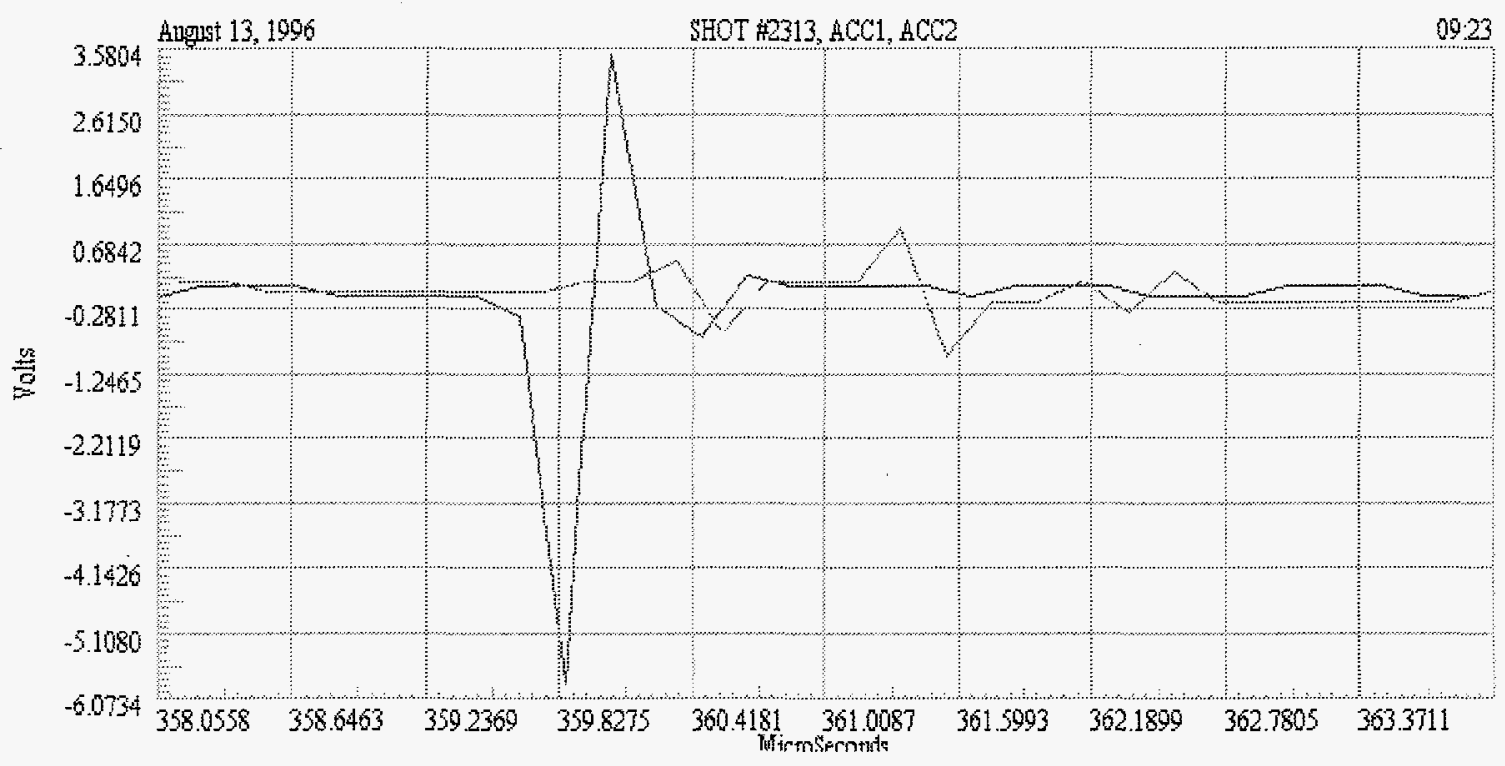

Figure 11. Line 23 and Line 24 accelerometer data, shot \#2313.

Four shock mount types were supplied by Media Recovery. Two different maximum G levels ( $250 \mathrm{Gs}$ and $500 \mathrm{Gs}$ ), with two different sensitivities in each range were used. L47 and L65 covered the $500 \mathrm{G}$ maximum range with 165 being the most sensitive. L75 and L85 spanned to 250 Gs. L85 was the most sensitive of these two. Media Recovery calibrated their devices for peak shock in the millisecond time span. Shock pulses on SATURN are in fractions of a microsecond. Because we were outside the calibrated range, responses might be random rather than predictable. Shot 2303 was monitored with these four types on all three PFLs. Table 1 shows which shock watch devices tripped.

Table 1. Results of shock watch devices.

\begin{tabular}{|c|c|c|c|}
\cline { 2 - 4 } \multicolumn{1}{c|}{} & Shock Indicator & $\begin{array}{c}\text { Shot } \\
\mathbf{2 3 0 3}\end{array}$ & \multicolumn{1}{c}{ Line 25 } \\
\cline { 2 - 4 } & Line 23 & Line 24 & \\
\hline Type 47 & & & Tripped \\
\hline Type 65 & & Tripped & Tripped \\
\hline Type 75 & Tripped & & Tripped \\
\hline Type 85 & Tripped & & \\
\hline
\end{tabular}

Line 24 with the shock mitigating pads tripped the most sensitive shock watch detector for each range. Lines 23 and 25 tripped only the $250 \mathrm{G}$ maximum indicators. Because these devices were used outside their calibrated range, it would be difficult to attach much meaning to their responses. 


\section{Analysis of Shock Watch Data}

Equations used throughout this document were created using MathCad ${ }^{\mathrm{TM}}$ 6.0. For the most part, defining terms and their use in an expression are self explanatory, e. g., pulsewidth, inverse, etc. The $\mathrm{g}_{47}, \mathrm{~g}_{65}$, etc. refer to a particular shock watch module. Their calibration graph will use the same two digit reference.

$$
\begin{aligned}
& \text { pulsewidth }=2.6 \cdot 10^{-3} \\
& \text { inverse }=\frac{1}{\text { pulsewidth }}
\end{aligned}
$$

The sensitivity of the shock watch modules increases with module number, 65 being more sensitive than 47,85 more sensitive than 75 . Types 47 and 65 have a calibrated span of 500 Gs, while 75 and 85 have a span of 250 Gs. The slope intercept equations and graphs were supplied by Media Recovery. In discussing the use of these devices with Media Recovery, they expressed that although the devices could be operated outside of their calibrated range, they could not guarantee the result. The information still may be useful.

$$
\begin{array}{r}
\mathrm{g}_{47}=233.1 \cdot \text { inverse }+52.7 \\
\mathrm{~g}_{47}=8.971 \cdot 10^{4} \\
\mathrm{~g}_{65}=201.1 \cdot \text { inverse }+25.1 \\
\mathrm{~g}_{65}=7.737 \cdot 10^{4} \\
\mathrm{~g}_{75}=193 \cdot \text { inverse }+17.2 \\
\mathrm{~g}_{75}=7.425 \cdot 10^{4} \\
\mathrm{~g}_{85}=187.8 \cdot \text { inverse }+10.6 \\
\mathrm{~g}_{85}=7.224 \cdot 10^{4}
\end{array}
$$

Response is in peak Gs

The calculated values for $\mathrm{g}_{47}, \mathrm{~g}_{65}, \mathrm{~g}_{75}$, and $\mathrm{g}_{85}$ are several orders of magnitude larger than indicated by accelerometer data. The numerical values are meaningless, but the pattern of tripped shock watch devices shown in Table 1 does give some useful information. Lines 23 and 25 are unmodified and both responded only to modules 75 and 85 . These two shock watch devices have the highest rate of change sensitivity for $G$ shock loading. Line 24 was modified with the polyurethane pads. The most sensitive shock watch module in each range tripped. This does seem to indicate that the shock wave had been spread out in time and diminished in peak amplitude. 


\section{High-Frequency Vibration Effects on SATURN}

As stated in the introduction, there are two components of the shock spectra that directly effect the life of components comprising SATURN. The low-frequency components contain most of the energy dissipated within the structure. This produces the physical damage to the PFLs in the form of cracked welds and torn metal. The high-frequency portion of the spectrum reduces the useful life of SATURN by vibrating parts until they loosen or fall off. A specific example is the water switch pin used on the PFLs. Although a locking mechanism (clamp or set screw) is used to keep the threaded pin aligned, the pins will loosen with time and use and become misaligned with the mating half of the gap switch. The problem arises because the required clamping force is a function of the frequency squared. Consequently, very high clamping forces are needed.

\section{Effects of Vibration on Threaded Sections}

Equating force to spring rates and peak accelerations units: acceleration $=1$ displacement $=1$ frequency $=1$ mass $=1$ spring_rate $=1$

force $=$ mass $\times$ acceleration acceleration $=\operatorname{displacement}(2 \pi \times \text { frequency })^{2}$

force $=$ spring_rate $\times$ displacement

Rearranging expressions, the spring rate can be given in terms of mass and frequency as follows.

$$
\text { spring_rate }=\operatorname{mass}(2 \pi \times \text { frequency })^{2}
$$

What becomes immediately apparent is the required spring rate to maintain clamping changes as a function of the frequency squared. This expression should be stated as an inequality, where the spring rate should always exceed maximum mass $x$ frequency ${ }^{2}$ forces to ensure that bolted parts do not loosen because of high frequency vibrations.

$$
\text { spring_rate }>\operatorname{mass}(2 \pi \times \text { frequency })^{2}
$$

In conjunction with acceleration/mass forces exceeding clamping forces, the resonance problems also come into play and will amplify all forces at the resonance nodal points. The general expression for axial resonance frequency is shown below.

$$
\mathrm{f}_{\text {axial resonance }}=\frac{1}{\text { length }} \sqrt{\frac{\text { modulus elasticity }}{\text { density }}}
$$

For example, a 1 -in. steel bolt, with a modulus of elasticity of $28,000 \mathrm{kpsi}$ has a natural frequency of approximately $200 \mathrm{KHz}$. By letting the bolt length increase to 2 inches, the natural frequency reduces to $100 \mathrm{KHz}$. To maintain the natural frequency as high as possible, minimal bolt lengths should be used in the assembly of parts. 


$$
\begin{aligned}
& f_{\text {steel }}=\frac{1}{1 \cdot \text { in }} \cdot\left(28 \cdot 10^{6} \cdot \frac{\mathrm{psi}}{490 \cdot \frac{\mathrm{lb}}{\mathrm{ft}^{3}}}\right)^{5} \\
& \mathrm{f}_{\text {steel }}=1.953 \cdot 10^{5} \cdot \mathrm{sec}^{-1}
\end{aligned}
$$

Axial resonance is approximately 200 kilocycles.

$$
\begin{gathered}
f_{\text {steel }}=\frac{1}{2 \cdot \text { in }} \cdot\left(38 \cdot 10^{6} \cdot \frac{\mathrm{psi}}{490 \cdot \frac{\mathrm{lb}}{\mathrm{ft}^{3}}}\right)^{5} \\
\mathrm{f}_{\text {steel }}=1.137 \cdot 10^{5} \cdot \mathrm{sec}^{-1}
\end{gathered}
$$

Axial resonance is approximately 100 kilocycles.

Changes in the modulus of elasticity have a much smaller effect on resonance than on excess bolt length. 


\section{Instrumentation and Analysis of Accelerometer Measurements}

Lines 23,24 , and 25 were chosen as the measurement site. These three lines are close to a junction box that permitted direct access to the basement cable screen room. The charge amplifiers for the accelerometers were located in this room. From this location, output signals from these charge amplifiers could be routed to the DAS.

The three PFL lines were identically instrumented for both wideband and low-pass measurements as shown in Figure 12. The difference between these two sets of measurements was the placement of a mechanical filter between the accelerometer and the brass mounting bolt. The filter is made of two nested stainless steel bodies coupled by butyl rubber, which damps high frequency by $12 \mathrm{~dB}$ /octave. The $-3 \mathrm{~dB}$ cutoff frequency is approximately $12 \mathrm{KHz}$.

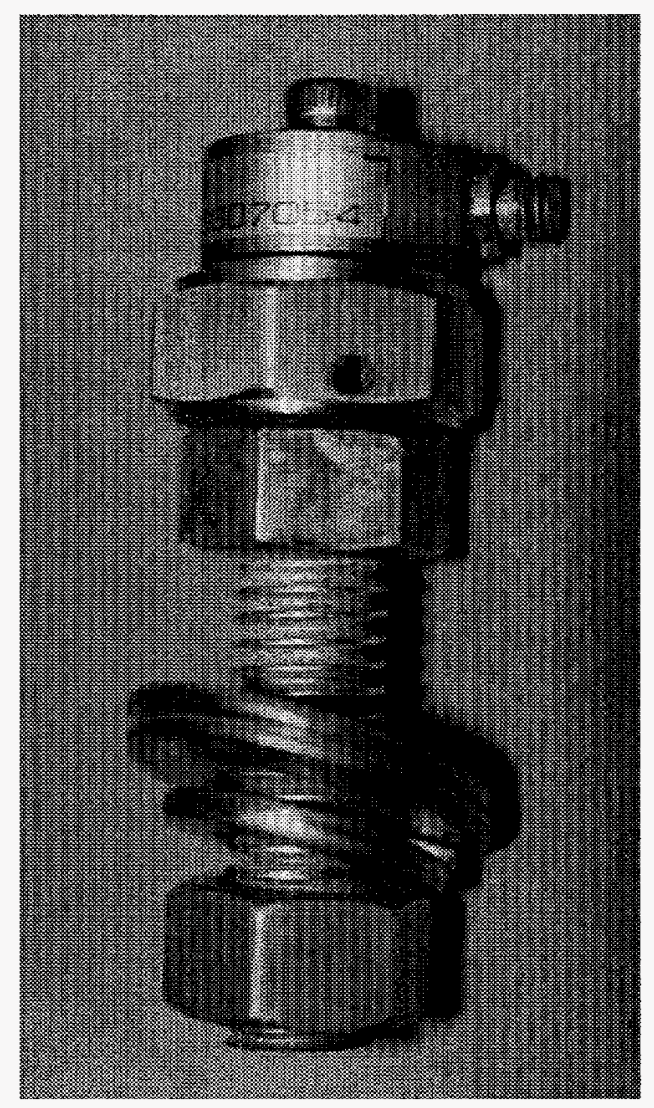

Figure 12. Typical accelerometer configuration.

Line 24 PFL was modified by placing 1/4-inch thick polyurethane pads between the bottom of the support stand and the steel tank floor. The restraining bolts were also modified to provide a large surface area for the nut to come down on another piece of polyurethane padding. This effectively 
floated the stand between polyurethane padding. Figure 13 shows the placement of the pads under line 24.

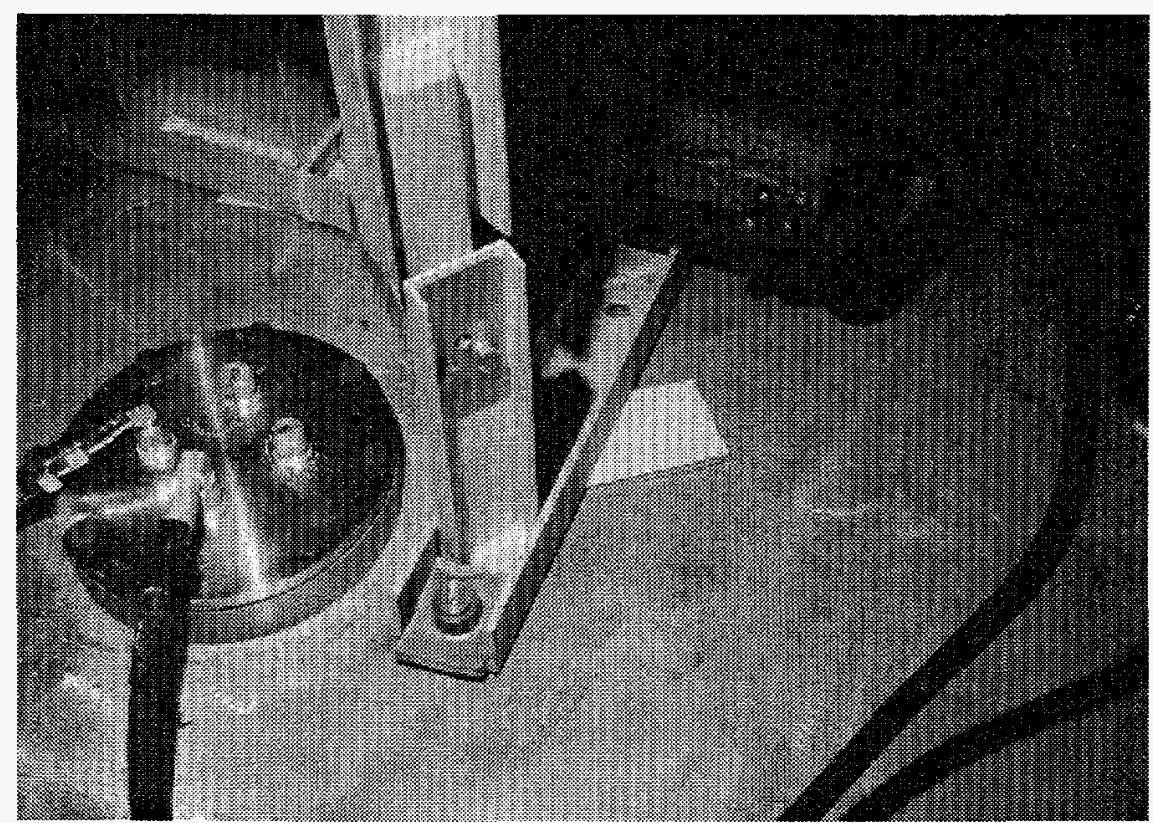

Figure 13. View of the bottom of the water section showing the placement of shock mitigating pads and snubbers under the bolt heads.

\section{Analysis of the Deformations and Fracturing of the PFLs at SATURN}

The damaged PFLs were fabricated from welded panels of 6061-T6 aluminum 1/4-inch plate. The tensile strength of this grade is 40,000 psi yield and 45,000 psi ultimate. These values are taken from the Reynolds Aluminum Handbook.

Peak acceleration loading with and without the benefit of shock mitigation is $50 \mathrm{Gs}$ and $200 \mathrm{Gs}$ as determined by accelerometer measurements.

The mass of the PFLs is approximately 500 pounds. This is a close estimate provided by the center section crew at SATURN. This provides enough information to make some comparisons of forces acting upon the monitored PFLs. Again the subscripts refer to measured peak g loading. First, the force acting on each line is determined.

$$
\begin{aligned}
& \text { force }_{50 \mathrm{~g}}=500 \mathrm{lb} \cdot 50 \mathrm{~g} \\
& \quad \text { force }_{50 \mathrm{~g}}=1.112 \cdot 10^{5} \cdot \mathrm{kg} \cdot \mathrm{m} \cdot \mathrm{sec}^{-2}
\end{aligned}
$$




$$
\begin{aligned}
& \text { force }_{200 \mathrm{~g}}=500 \mathrm{lb} \cdot 200 \mathrm{~g} \\
& \qquad \text { force }_{200 \mathrm{~g}}=4.448 \cdot 10^{5} \cdot \mathrm{kg} \cdot \mathrm{m} \cdot \mathrm{sec}^{-2}
\end{aligned}
$$

Then the load per square inch is determined for each line.

$$
\begin{aligned}
& \text { yield }_{50 \mathrm{~g}}={\text { force } 50 \mathrm{~g} \cdot \frac{1}{\mathrm{in}^{2}}} \\
& \operatorname{yield}_{50 \mathrm{~g}}=1.724 \cdot 10^{8} \cdot \mathrm{kg} \cdot \mathrm{m}^{-1} \cdot \mathrm{sec}^{-2}
\end{aligned}
$$

Force per square inch for a $50 \mathrm{~g}$ load.

$$
\begin{aligned}
& \text { yield }_{200 \mathrm{~g}}=\text { force } 200 \mathrm{~g} \cdot \frac{1}{\mathrm{in}^{2}} \\
& \text { yield }_{200 \mathrm{~g}}=6.895 \cdot 10^{8} \cdot \mathrm{kg} \cdot \mathrm{m}^{-1} \cdot \mathrm{sec}^{-2}
\end{aligned}
$$

Force per square inch for a 200g load.

The ratio between peak shock loads and yield strengths for the aluminum can be determined.

$$
\begin{aligned}
& \text { aluminum }_{6061 \_\mathrm{T} 6}=40,000 \mathrm{psi} \\
& \text { yield strength of } 6061 \text { aluminum } \\
& \text { ratio }_{50 \mathrm{~g}}=\frac{\text { yield }_{50 \mathrm{~g}}}{\text { aluminum }_{6061 \_\mathrm{T} 6}} \\
& \text { ratio }_{50 \mathrm{~g}}=0.625
\end{aligned}
$$

Yield strength of the aluminum PFL is not exceeded by peak acceleration loading.

$$
\begin{gathered}
\text { ratio }_{200 \mathrm{~g}}=\frac{\text { yield }_{200 \mathrm{~g}}}{\text { aluminum }_{6061 \_\mathrm{T} 6}} \\
\text { ratio }_{200 \mathrm{~g}}=2.5
\end{gathered}
$$

Yield strength of the aluminum PFL is exceeded by peak acceleration loading. 
The values of 50 Gs and 200 Gs are average values measured over a series of shots on SATURN. Shot waveforms shown in this report are typical. 


\section{Suggestions for Future Accelerators}

The most dramatic number determined in this study is the ratio of yield strengths of the aluminum to the peak shock loads measured on line 24. This line had less than 100 square inches of polyurethane padding under the PFL stand. This value of 0.625 shows that with a simple, cheap shock absorbing pad under the PFL mounting stand, peak imposed forces are well below maximum strength of the PFL. Placement of these pads under all thirty six lines will greatly reduce the stresses imposed on SATURN. This should lead to lower maintenance costs and longer life of the facility.

The analysis of bolt vibration leading to the failure of bolted sections was also determined. Axial resonance of a bolt is the primary reason for failure. Proper strength bolts with minimum required length to achieve bolting together two or more parts is necessary. Uniformly torque all bolts on a part to insure even distribution of the load. The clamping force must exceed the vibrational forces to insure that bolts do not vibrate loose. Since these vibrational forces are a function of the frequency squared, additional clamping force may be achieved by use of a Belleville washer. The washer can flex while still maintaining a constant pressure under the head of a bolt. 


\section{Appendix A. Calibration Graphs for Media Recovery Shock Watch}

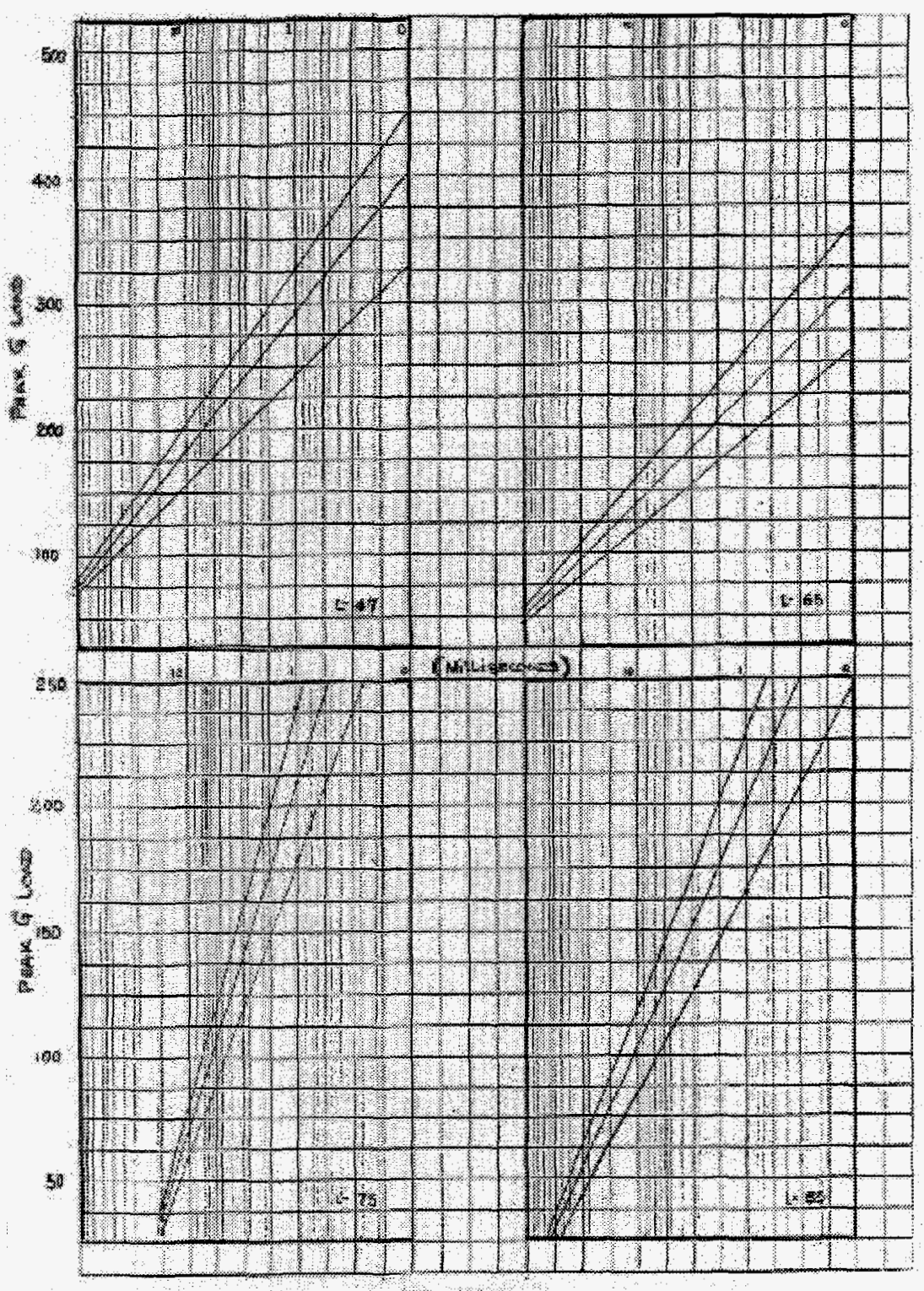




\section{Appendix B. Brüel \& Kjær UA0553 and UA0559 Specification Sheet}




\section{Brüel \& Kjæer}

\section{Mechanical Filter for Accelerometers}

USES:

- General vibration measurements, particularly where instrumentation is not equipped with a choice of low-pass filters

- Measurement of low frequency, low level vibration which is masked by high frequency, high acceleration levels often found in hand held power tools.

- Protection of accelerometer and preamplifier from high level shocks

- Decreases sensitivity to transverse vibrations
FEATURES:

- Prevents the accelerometer from detecting high frequency vibration

- Prevents the excitation of accelerometer resonance

- Usable with all types of piezoelectric accelerometers

- Cut-off frequency selected by adjusting the load mass

- Breaks ground-loop paths
Mechanical Filter UA 0559 is interposed between an accelerometer and the mounting point on the test object in order to prevent the accelerometer from detecting high frequency vibration. There are several instances where this may be desirable:

1) Where it is wished to measure low frequency vibration, possibly at low levels, and where high level, high frequency acceleration masks the low frequency components because of preamplifier overload, distortion, lack of electronic filters etc.

2) Where the accelerometer's resonance frequency is being excited by high frequency vibration of possibly insignificant level, causing wideband measuring errors and overload. Thus by using the mechanical filter the useful dynamic range of measuring instruments is increased by more than $20 \mathrm{~dB}$.

3) Where it is feared that the accelerometer could be subjected to transient shock levels beyond its maximum capability, thus preventing damage.

4) Where the measuring instrumentation has a high frequency response in excess of that required and is not equipped with suitable low-pass filters. Vibration measurement with a wide-band sound level meter is a notable example of this case.

5) Where it is wished to obtain a specific cut-off frequency without the use

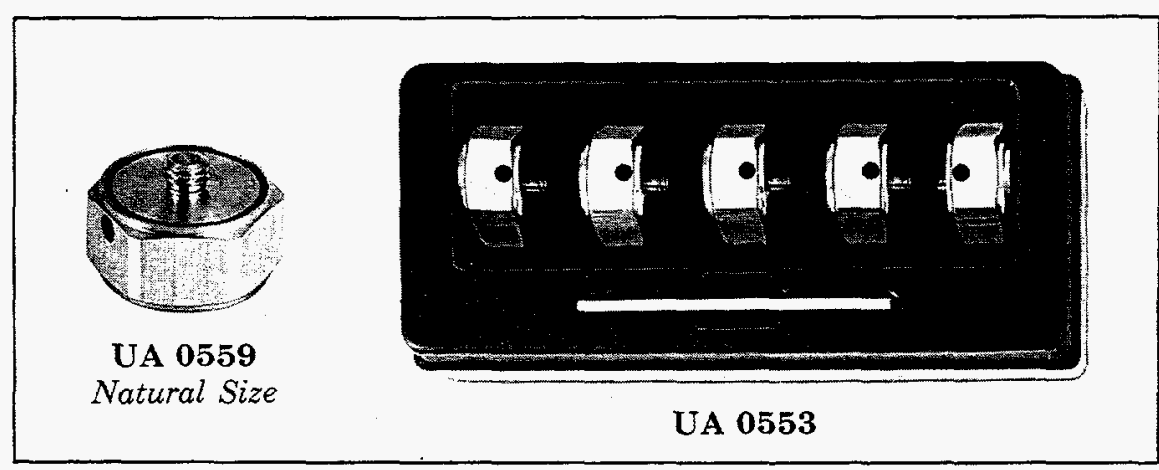

of specially built electronic filters or elaborate tunable filters. For example, when measuring vibration as applied to the human hand, arm or body, the measuring range is normally limited to below $1000 \mathrm{~Hz}$.

The effect of the mechanical filter on the frequency response of an accelerometer is shown in Fig.1. Transverse and main axis resonances which are typically $30 \mathrm{~dB}$ in amplitude are substituted by a highly damped resonance response of only 3 to $4 \mathrm{~dB}$ amplitude. The accelerometer's own axial resonance is suppressed by 25 to $30 \mathrm{~dB}$ and shifted up in frequency due to decoupling of the mass above the filter.

If a particular accelerometer, when combined with the mechanical filter, does not cover a high enough frequency, an accelerometer with a lower mass should be used, see Fig.2. Conversely if it is wished to reduce the cut-off frequency at the high frequency end additional mass loads can be added.

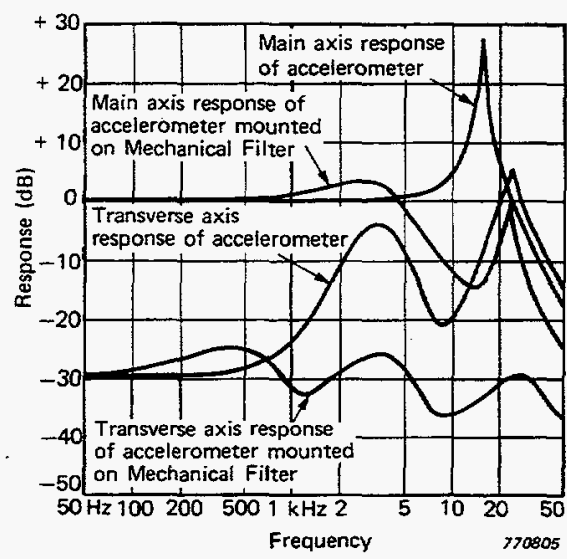

Fig. 1. Typical main axis and transverse axis frequency response of Accelerometer Type 4370, demonstrating the effect of the Mechanical Filter UA 0559

These can be added in the form of suitable washers or nuts. The curve in Fig.3 plots the cut-off frequency $(-3 \mathrm{~dB})$ as a function of the load mass on the filter.

The mechanical filter can be used to isolate the accelerometer from trans- 


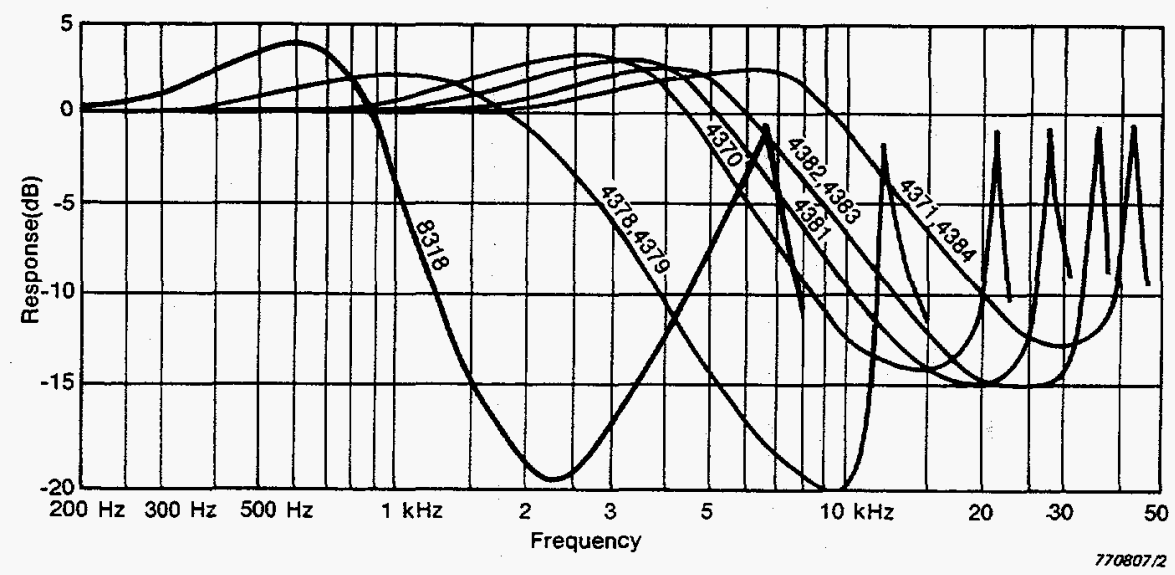

Fig. 2. Typical frequency response of various $B \& \mathrm{~K}$ general purpose accelerometers when mounted on UA 0559

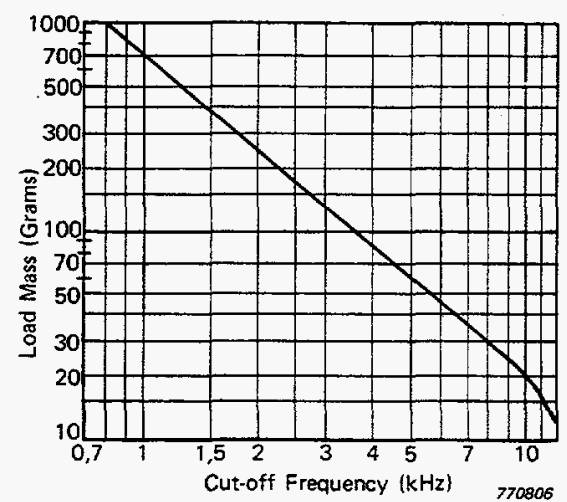

Fig. 3. Typical Cut-off frequency $(-3 d B)$ plotted as a function of load mass on filter

verse vibrations. This is particulary useful when measuring complex vibration environments.

Although it is quite possible to use the mechanical filter with accelerometers which have a larger base radius than itself, care must be taken with bient temperatures between $20^{\circ}$ and $50^{\circ} \mathrm{C}$. At higher temperatures the stiffness and damping are reduced resulting in a reduction in resonant frequency and an increase in the amplification at resonance. For lower temperatures the resonant frequency is increased while the amplification at resonance is also increased. These characteristics are plotted in Fig.4.

The filter consists of an upper and lower part of stainless steel bonded together and electrically separated by a specially formulated butyl rubber core. The two halves are equipped with standard accelerometer threads (10 - 32 UNF), male and female respectively. A tommy bar can be inserted transversely through the two halves to relieve the rubber core of excessive twisting torque when the accelerometer is tightened down. Where the butyl rubber core can be contaminated with hydrocarbon substances such as oil or fuel, a resistant silicone rubber sealer should be used (e.g. Dow Corning Type 733 RTV). The filters are supplied in packs of 5 under part No. UA 0553.
The stiffness and damping effect of the filter medium, butyl rubber, is dependent on ambient temperature, optimum damping being obtained at am-

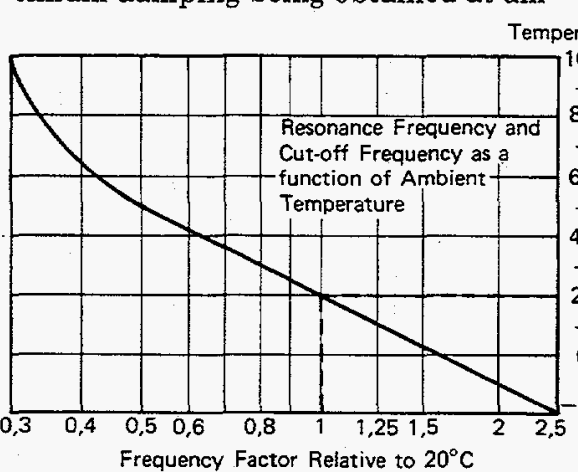

Temperature ${ }^{\circ} \mathrm{C}$

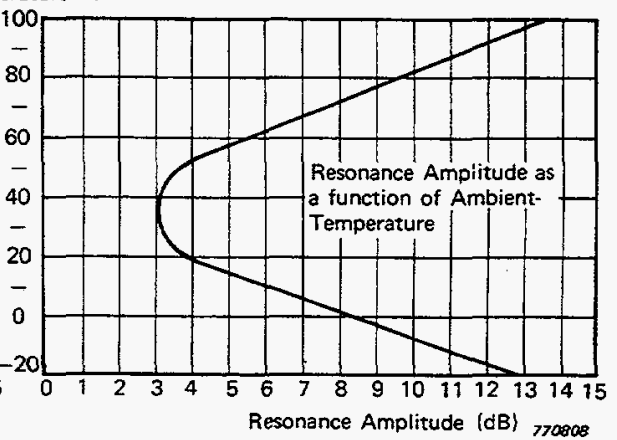

Fig. 4. Typical temperature response of UA 0559

\section{Specifications UA 0553 and UA 0559}

\begin{tabular}{|c|c|c|}
\hline $\begin{array}{l}\text { Response at Resonance: }<+4 \mathrm{~dB}(+60 \%) \\
\text { for temperatures }+20^{\circ} \mathrm{C} \text { to }+50^{\circ} \mathrm{C} \text {. See Fig. } \\
\text { Cut-of Frequency }(-3 \mathrm{~dB}) \text { : At } 20^{\circ} \mathrm{C} \text {, approx. } \\
35 \% \text { of accelerometer's normal mounted res- } \\
\text { onance frequency. Is a function of load-mass } \\
\text { and temperature, se Fig. } 3 \text { and Fig. } 4 \\
\text { Filter Slope: Approx. } 12 \mathrm{~dB} / \mathrm{Octave} \\
\text { Temperature Range: }-50^{\circ} \mathrm{C} \text { to } 100^{\circ} \mathrm{C} \\
\text { Transmission Linearity: Less than } 2 \% \text { up to } \\
10 N_{\text {RMs }} \text { dynamic load } \\
\text { Electrical Resistance: }>100 \mathrm{M} \Omega \text { top to base }\end{array}$ & $\begin{array}{l}\text { Dimensions: } \\
\text { Mounting Surface } \\
\text { Through hole } \\
\text { Spanner Size across flats } \\
\text { Recess } 6,5 \text { dia. } \\
0,4 \text { deep } \\
\text { Tramensions in mm. }\end{array}$ & $\begin{array}{l}\text { Max. Continous Dynamic Load: } 30 \mathrm{~N}_{\mathrm{RMS}} \text { axi- } \\
\text { al (corresponding to } 550 \mathrm{~m} / \mathrm{s}^{2}(\sim 55 \mathrm{~g} \text { ) with } 54 \\
\text { gram accelerometer (Type } 4370) \text { ), } 15 \mathrm{Nm}_{\mathrm{FMS}} \\
\text { transverse } \\
\text { Max. Accelerometer Mounting Torque: } \\
\text { I Nm } \\
\text { Using tommy bar } 7 \mathrm{NM} \\
\text { Weight: } 16 \mathrm{~g} \\
\text { Materials: Stainless steel AISI } 303 . \text { Butyl rub- } \\
\text { ber } \\
\text { Accessories Included: } \\
\text { Set UA } 0553 \text { contains: } \\
5 \text { Filters................................................. UA } 0559 \\
1 \text { Tommy bar........................................ DA } 1084\end{array}$ \\
\hline
\end{tabular}

\section{Brüel Kjar}

\section{Bruel \& Kjaer Instruments, inc.}




\section{Distribution}

$\begin{array}{lrl}1 & \text { MS 1106 } & \text { A. W. Sharpe, 9342 } \\ 5 & 1106 & \text { R. E. Craven, 9342 } \\ 1 & 1106 & \text { K. Mikkelson, 9342 } \\ 1 & 1106 & \text { J. S. Gustwiller, 9342 } \\ 1 & 1106 & \text { R. L. Westfall, 9342 } \\ 1 & 1165 & \text { J. E. Powell, 9300 } \\ 1 & 1165 & \text { D. B. Hughes, 9309 } \\ 1 & 1179 & \text { J. L. Lee, 9341 } \\ 1 & 1159 & \text { M. Hedemann, 9311 } \\ 1 & 1193 & \text { D. Bloomquist, 9536 } \\ 1 & 1196 & \text { W. A. Stygar, 9577 } \\ 1 & 1194 & \text { R. B. Speilman, 9573 } \\ & & \text { B. P. Peyton, 9342 } \\ & & \text { B. M. Henderson, 9342 } \\ 1 & 9018 & \text { Central Technical Files, 8940-2 } \\ 5 & 0899 & \text { Technical Library, 4916 } \\ 2 & 0619 & \text { Review and Approval Desk, 12690 } \\ & & \text { for DOE/OSTI }\end{array}$

